\title{
Hypothesis
}

\section{Which Memory System is Impaired First in Alzheimer's Disease?}

\author{
Mira Didic ${ }^{\mathrm{a}, *}$, Emmanuel J. Barbeau ${ }^{\mathrm{b}}$, Olivier Felician ${ }^{\mathrm{a}}$, Eve Tramoni ${ }^{\mathrm{a}}$, Eric Guedj ${ }^{\mathrm{c}}$, \\ Michel Poncet ${ }^{\mathrm{a}}$ and Mathieu Ceccaldi ${ }^{\mathrm{a}}$ \\ ${ }^{a}$ Service de Neurologie and Neuropsychologie, Pôle de neurosciences cliniques, AP-HM Timone, INSERM U751, \\ Université de la Méditerranée, Marseille, France \\ ${ }^{\mathrm{b}}$ Université de Toulouse, UPS, Centre de Recherche Cerveau et Cognition, France CNRS, CerCo, Toulouse, France \\ ${ }^{\mathrm{c}}$ Service Central de Biophysique et Médecine Nucléaire, Centre Européen de Recherche en Imagerie Médicale \\ (CERIMED), AP-HM \& Faculté de Médecine, Université de la Méditerranée, Marseille, France
}

Handling Associate Editor: Flavio Nobili

Accepted 6 June 2011

\begin{abstract}
Diagnosis of Alzheimer's disease (AD) in its earliest stages becomes increasingly important as disease modifying agents are being developed. In this area of research, many clinical and neuroimaging studies focus on markers of hippocampal dysfunction. However, during the "transentorhinal stage" of AD, neurofibrillary tangles (NFT), related to tau protein pathology, develop in the anterior subhippocampal (perirhinal/entorhinal) cortex before the hippocampus. NFT are tightly correlated with clinical symptoms. Therefore, an accurate understanding of the behavioral correlate of transentorhinal dysfunction could critically contribute to the early diagnosis of the disease. Recent findings from studies in animals and human brain-damaged patients suggest that the anterior subhippocampal region, functionally integrated into an anterior mesiotemporal network, is involved in object based context-free memory. In this article, we evaluate the hypothesis according to which tau deposition in the anterior subhippocampal region during the earliest stages of the most common form of AD, with predominant MTL dysfunction, will lead to dysfunction of neural networks implicated in context-free memory. We challenge the view that impaired episodic memory is the hallmark of early AD. Instead, a model that integrates the localization and temporal sequence of NFT within the mesial temporal lobe (MTL) is proposed. Paralleling the development of NFT in anterior subhippocampal areas, impaired context-free, object-based, memory could be the first detectable sign in AD. In a subsequent, "hippocampal" stage, context-rich, episodic and spatial memory, becomes altered as well. The question as to the "episodic" nature of "episodic memory tasks" is also addressed.
\end{abstract}

Keywords: Alzheimer's disease, amnesia, entorhinal cortex, hippocampus, memory, mesial temporal lobe, perirhinal cortex

"By the time I wrote Elements of Episodic Memory [1], it had become possible to entertain the thought that the heuristic distinction was useful for the simple reason that it corresponded to biological reality. I proposed, therefore, that episodic

\footnotetext{
*Correspondence to: Mira Didic, MD, PhD, Centre HospitaloUniversitaire de la Timone, 264, rue Saint Pierre, 13385 Marseille Cedex 5., France. Tel.: +33 4913859 28; Fax: +33 4913849 22; E-mail: mira.didic@ap-hm.fr.
}

and semantic memory represented two functionally separable memory systems. In Elements I also made a confession: I had been wrong in 1972 when I had assumed that the traditional, Ebbinghaus-inspired, study/test laboratory experiments of verbal learning and memory had dealt with episodic memory. They had not. Two importantfeatures of episodic memory were missing. One had to do with the contents of what the subjects in 
the experiments had to learn. Episodic memory is about happenings in particular places at particular times, or about "what", "where," and "when" $[2$, 3]. Traditional laboratory experiments, however, were almost invariably concerned with "what." Subjects are asked, "What do you remember of the presented material?" They report their knowledge in tests such as free recall, cued recall, or recognition. Subjects' memory for "where" and "when" was hardly ever examined. (... )" Endel Tulving [4].

\section{INTRODUCTION}

During the earliest stages of many neurodegenerative diseases, like amyotrophic lateral sclerosis, Parkinson's disease, or multisystem atrophy, clinical symptoms are clearly related to the disruption of one anatomo-functional system. There is evidence that large scale human brain networks involved in cognition present a selective vulnerability in neurodegenerative disease [5, 6]. In Alzheimer's disease (AD), findings from neuropathological studies indicate that the integrity of neural systems related to memory is compromised by the loss of projections between and among the entorhinal cortex (ERC), the hippocampus $(\mathrm{H})$, and the amygdala, as well as subcortical nuclei and paralimbic cortices such as the temporo-polar cortex (TPC) [7]. The general idea developed in this hypothesis article is that studies that focus on the function of neural networks affected by pathological lesions in the earliest stages of $\mathrm{AD}$ could improve the understanding of clinical signs of predementia AD.

A better understanding of memory systems affected early in $\mathrm{AD}$ equally has important implications for early diagnosis. The current development of disease modifying therapeutic agents requires reliable identification of patients when neuropathological changes are minimal. Despite major advances in the development of structural/molecular neuroimaging and cerebrospinal fluid (CSF) biomarkers, adding results from the cognitive assessment considerably contributes to the identification of $\mathrm{AD}$ in patients with mild cognitive impairment (MCI) [8]. However, which type of cognitive dysfunction should be looked for and which tasks should be used remains controversial [9].

$\mathrm{AD}$ is characterized by amyloid and tau deposition, as well as neuronal and synaptic loss. Neurofibrillary tangles (NFT), related to tau protein pathology and associated with clinical signs [10-12], first develop in the mesial temporal lobe (MTL) [13-14]. This brain

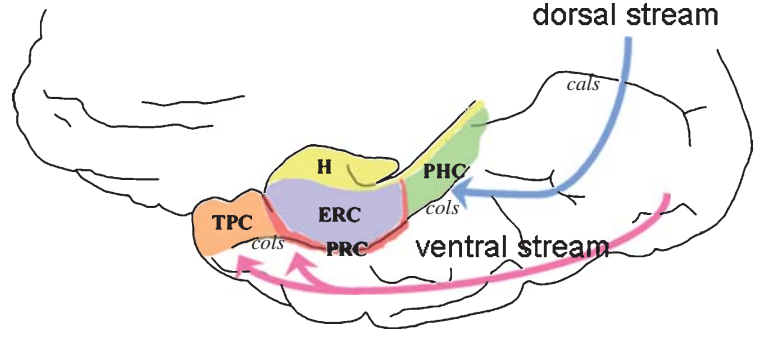

Fig. 1. Medial view of the right temporal lobe, along with a schematic representation of MTL structures. H: hippocampus; ERC: entorhinal cortex; PRC: perirhinal cortex; TPC: temporopolar cortex; PHC: parahippocampal cortex; cols: collateral sulcus; cals: calcarine sulcus. The posterior limits of the $\mathrm{H}$ and $\mathrm{PHC}$ are not represented. Note that the PRC lies mainly within the collateral sulcus. Adapted from Barbeau et al. [38].

region is crucial for declarative memory [15]. Within declarative memory, a distinction between episodic and semantic memory was introduced by Tulving [16]. Many studies report that anterograde episodic learning is impaired in patients with predementia $\mathrm{AD}$ (see [17, 18] for reviews). Moreover, it was recently suggested that impaired episodic memory is a core symptom that should be integrated into the diagnosis of predementia AD [19]. However, recent advances on the function of subcomponents of the MTL are rarely taken into account.

The MTL is composed of several subregions that contribute to declarative memory, the $\mathrm{H}$ as well as the perirhinal (PRC), ERC, and parahippocampal cortices (PHC). Henceforth, the PRC and the ERC will sometimes be referred to as "anterior subhippocampal" structures for the sake of simplicity. These subcomponents are interconnected with distinct cortical association areas, thus forming distinct mesiotemporal networks. There is increasing evidence for a differential contribution of these subcomponents of the MTL to declarative memory. Anterior subhippocampal structures play a crucial role in "context-free memory", or long term memory of learned information which is dissociable from the context of learning when required to be recalled or recognized (memory for objects, facts and concepts), while the $\mathrm{H}$ plays a critical role in "context-rich memory" or long term memory of learned information that is embedded into a context (like spatial and episodic memory) [20-23]. If the role of each of these structures is specific, the resulting memory dysfunction in $\mathrm{AD}$ should depend on the topographical distribution of NFT. In this way, the different neuropathological stages, which initially affect a subregion of the PRC, then the ERC before spreading to the $H[13,14]$, should result in distinct types of 
memory impairment. Our hypothesis is that tau deposition in the anterior subhippocampal region during the earliest stage of $\mathrm{AD}$ will lead to dysfunction of neural networks implicated in context-free memory.

\section{Early $A D$ and the subhippocampal stage}

NFT, which are composed of abnormally phosphorylated tau protein that develops in the nerve cell body and are associated with cognitive deficits [10-12], initially appear in the MTL in the most common form of $\mathrm{AD}(\sim 85 \%$ of the cases [24]), spreading through its subcomponents in a sequential fashion. Several studies demonstrate that NFT initially develop in the medial portion of the PRC, the transentorhinal cortex (TERC, or BA35) [25], then progress to the ERC, before reaching the $\mathrm{H}$ in the limbic stage and later affect the temporal neocortex $[13,14,26]$. Within the H, NFT first appear in the CA1 subfield, mainly represented in the head of the $\mathrm{H}$ [27]. Although the topography, as well as the inter-personal variability, of these anterior subhippocampal structures (PRC/ERC) makes the neuroimaging assessment of this brain region difficult, potential non-invasive diagnostic tools that could reliably detect subtle pathological changes at the "subhippocampal" stage of AD are currently receiving increasing interest. Using MRI, several studies demonstrate atrophy of the ERC in predementia AD [28-32]. Baseline ERC volume has been shown to be a better predictor for decline from MCI to AD than hippocampal volume [28, 30].

\section{Anatomy and connectivity of the MTL}

In addition to the $\mathrm{H}$, the MTL consists of several strongly interlinked subcomponents, the PRC (BA35 medially and BA36 laterally), the ERC (BA28), distributed along the anterior part of the collateral sulcus and parahippocampal gyrus, as well as the PHC (parahippocampal cortex) which lies on the posterior parahippocampal gyrus. Furthermore, the medial part of the temporo-polar cortex (TPC) (BA38), functionally part of a wider PRC region, is also viewed upon as an extension of BA36 by some authors [33-36], and hence as part of the "total" PRC for others [37].

The MTL is connected with neocortical and subcortical regions. Studies in monkeys and rodents show that distinct subregions of the MTL are connected to distinct cortical association areas through parallel pathways. Sensory information from widespread areas of the neocortex enters the MTL primarily via projections to the PRC and the PHC. The PRC mainly receives projections from ventral processing streams, and in particular nearly two-thirds of its cortical inputs from the adjacent ventral-stream visual areas [33]. Compared with the PRC, the $\mathrm{PHC}$ receives a far greater proportion of its inputs from dorsal-stream areas, including the posterior parietal cortex, the retrosplenial cortex, the dorso-lateral prefrontal cortex, and the dorsal bank of the superior temporal sulcus [33, $39,40]$. Thus, two major parallel networks are interconnected with the MTL.

Both, the PRC and PHC feed information into the ERC [41, 42]. The PHC projects mainly to the medial entorhinal area, whereas the PRC projects principally to the lateral entorhinal area. The ERC, in turn, projects to the $\mathrm{H}$ [43]. Moreover, these parallel pathways are interconnected with projections from the PHC to the PRC, in addition to connections between the lateral and the medial areas of the ERC [33, 40, 44-47].

In the human brain, connectivity studies using functional measurements of resting-state activity on high-resolution MRI recently identified two separate cortical networks that each associate with distinct subregions of the MTL [48]. An "anterior MTL network" involves the anterior lateral temporal lobe, along with the middle temporal gyrus, immediately below the superior temporal sulcus, as well as the PRC and the ERC. This pathway converges on the head of the $H$. The second network, or "posterior MTL network" involves the inferior parietal lobule, the retrosplenial cortex, the posterior cingulate cortex, and a portion of the ventral medial prefrontal cortex. It includes the PHC, and converges on the body of the $\mathrm{H}$. Overall, the identification of these two pathways in humans provides an anatomic reference for further studies.

Finally, there is also evidence that some segregation is still maintained among the subcortical projections from the MTL since the PRC mainly project to the dorso-median nuclei of the thalamus, while the $\mathrm{H}$ mainly projects to anterior thalamic nuclei and henceforth to an "extended hippocampal system" involving posterior cingulate areas and the retrosplenial cortices [22].

\section{Parallel MTL networks involved in declarative memory}

That the MTL is crucial for anterograde declarative memory has been confirmed by many studies since the description of the patient HM, a patient who suffered from amnesia after bilateral surgical removal of the MTL for intractable epilepsy [49]. The MTL is crucial for both semantic and episodic memory. Semantic 
memory refers to facts (as knowledge of objects, concepts, people, and words). Episodic memory refers to events with a unique spatiotemporal reference that requires mental time travel through subjective time, thus allowing the retrieval of previous experiences [1]. There are two main views of how declarative memory is organized within the MTL. One view argues that the MTL is a set of structures contributing to declarative memory in a rather homogenous way [50]. An alternative view is that subregions of the MTL, although strongly interlinked, make different functional contributions to anterograde declarative memory [20-23].

Over the past years, there has been largely converging evidence for the functional specialization of the different areas of the MTL. Studies in nonhuman primates indicate that the PRC is crucial for "context-free" memory as assessed by visual recognition memory (VRM) tasks [51]. This brain area is also thought to play a critical role in processes comparable with non-verbal aspects of human semantic memory [52]. By contrast, experimental studies in animals support the evidence that the $\mathrm{H}$ is a key node for "context-rich memory" [53-55]. Mishkin and colleagues [20], following a critical study by VarghaKhadem et al. [56] in three adolescents who had suffered from anoxia, suggested in a "hierarchical model of cognitive memory" that the neural substrate for "context-free memory", could be dissociated from "context-rich memory" in the human brain. Unlike non-human primates, for whom connectivity with the PRC is predominantly visual [33, 34], the PRC in humans receives information that is expanded beyond what is found in macaque, with highly processed sig- nals from large regions of lateral temporal association cortex [48].

Similarly, Aggleton and Brown [57] provided evidence for a distinction between two recognition memory systems involving MTL structures through a dual process model, one system being crucial for familiarity judgments, while the other is thought to be critical for recollection. While familiarity is contextfree, giving a sense of prior exposure, recollection is defined as a conscious retrieval of context-rich material and associations. Although these two models significantly differ in many aspects, they converge to the notion that within the MTL, the neural substrate of context-free memory like facts based on familiarity judgment might be segregated from the neural substrate for events based on recollection. Moreover, these two models converge concerning the involvement of brain structures, since context-free memory as well as familiarity, are thought to depend on anterior subhippocampal areas (among which the PRC plays a key role), while context-rich processes such as recollection, is thought to depend on the $\mathrm{H}$. This functional segregation is also supported by neuroimaging (for review, see [58]) and electrophysiological (for review, see [59]) studies.

An increasing number of studies in MTL-injured patients are also in favor of a distinct contribution of the subregions of the MTL to memory [56, 60-64]. Patients with $\mathrm{H}$ lesions are impaired on tasks assessing context-rich material, which involve spatial memory, recall for personal events or episodic memory, but show intact memory for context-free material as facts (i.e., semantic memory) or familiarity based recogni-

Table 1

Overview of several studies that provide evidence for different contributions of the subcomponents of the MTL to declarative memory

\begin{tabular}{|c|c|c|}
\hline Reference & Impaired & Preserved \\
\hline \multicolumn{3}{|c|}{ Studies of patients with damage to the hippocampus only } \\
\hline $\begin{array}{l}\text { Vargha-Khadem et al. (1997) Science [56] } \\
\text { Mayes et al. (2002) Hippocampus [60] } \\
\text { Aggleton et al. (2005) Neuropsychologia [61] } \\
\text { Bastin et al. (2004) Neurocase [65] } \\
\text { Barbeau et al. (2005) Hippocampus [62] } \\
\text { Lebrun-Givois et al. (2008) Rev Neurol [63] } \\
\text { Tramoni et al. (2011) Brain [64] }\end{array}$ & $\begin{array}{l}\text { episodic and spatial memory } \\
\text { episodic memory } \\
\text { recollection } \\
\text { recall } \\
\text { visual recall } \\
\text { episodic memory } \\
\text { context-rich memory (long term) }\end{array}$ & $\begin{array}{l}\text { semantic memory and recognition memory } \\
\text { recognition memory } \\
\text { familiarity in recognition memory } \\
\text { Recognition } \\
\text { visual recognition } \\
\text { semantic memory } \\
\text { context-free memory (long term) }\end{array}$ \\
\hline \multicolumn{3}{|c|}{$\begin{array}{l}\text { Studies of patients with MTL damage leaving the hippocampus (at least partially) } \\
\text { intact and/or with impaired familiarity but preserved recollection }\end{array}$} \\
\hline $\begin{array}{l}\text { Temple and Richardson (2006) Cogn Neuropsychol [70] } \\
\text { Barbeau et al. (2006) Cogn Neuropsychol [69] } \\
\text { Bowles et al. (2007) Proc Natl Acad Sci 2007 [67] } \\
\text { Bowles et al. (2010) Neuropsychologia [68] } \\
\text { Barbeau et al. (2011) Hippocampus [66] } \\
\text { Martin et al. (2011) Neuropsychologia [74] }\end{array}$ & $\begin{array}{l}\text { semantic memory } \\
\text { context-free memory } \\
\text { familiarity } \\
\text { familiarity } \\
\text { visual recognition memory } \\
\text { familiarity }\end{array}$ & $\begin{array}{l}\text { episodic memory } \\
\text { context-rich memory } \\
\text { recollection } \\
\text { recollection } \\
\text { visual recall } \\
\text { recollection }\end{array}$ \\
\hline
\end{tabular}


tion when anterior subhippocampal areas are intact [56, $60,62,65]$.

The reverse dissociation, impaired memory for facts contrasting with intact memory for events is more rarely reported [66-70]. In semantic dementia, a degenerative condition with impaired context-free memory for objects and facts and preserved episodic memory [71], atrophy of both the PRC, the anterior $\mathrm{ERC}$ and the TPC, but also the $\mathrm{H}$ has been described, PRC volume correlating positively with performance on semantic memory tasks [72, 73].

Taken together, a number of studies in patients suggest that brain damage in regions within anterior subhippocampal areas lead to impaired context-free memory. By contrast, damage to brain regions that are part of a posterior MTL network, like the $\mathrm{H}$, appear crucial for context-rich memory, such as episodic memory and spatial memory. In Table 1, we provide an overview of several studies that provide evidence for different contributions of the subcomponents of the MTL to declarative memory [56, 60-70, 74].

\section{Impaired context-free memory in early stages of $A D$}

In this section, we will provide several examples of the tasks found to be impaired in the earliest stages of clinical AD. The interesting point here is that many of the so-called "episodic" memory tasks that patients fail on in the earliest stages of AD are in fact largely context-free in nature. In particular, most of these tasks mainly evaluate retrograde semantic memory or anterograde learning of single items (such as word lists, pictures of objects, or faces), which can be encoded, stored and later recognized or recalled independently one from the other with no reference to the context of learning.

In studies on asymptomatic subjects at risk for autosomal dominant $\mathrm{AD}$, patients who later developed the disease showed impaired performance on recognition memory tasks using words or faces as early as 6 years before diagnosis [75]. A longitudinal case study of a patient with the APPV717I (London) mutation, clinically presenting with pure progressive amnesia over an extended period of at least 13 years, equally showed impaired performance on tasks assessing context-free memory like the Recognition Memory Tests for single items like words or faces at the predementia stage [76].

Population-based studies in healthy community dwellers, likely to reveal the earliest stages in $\mathrm{AD}$, mainly show deficits on tasks assessing semantic mem- ory, concept formation, and recall of words [77-81]. Focusing on patients at risk for decline, among the neuropsychological tasks assessing memory that are useful in predicting AD, are the FCSRT (Free and Cued Selective Reminding test) and the RAVLT (Rey's Auditory-Verbal Learning Task) [82, 83]. These tasks all evaluate the ability to recall context-free material like words. In a PET-study, performance on a word list learning task was correlated with glucose metabolism in the entorhinal cortex [84]. In addition, several studies recently consistently demonstrated an impairment of semantic memory in patients at risk for $\mathrm{AD}$, including MCI-patients who later converted to AD [81, 85-92]. Two of these studies found that the neural correlate of this semantic impairment involves anterior subhippocampal structures [93, 92]. Moreover, some studies take the dysfunction resulting from earliest tau-related pathology in anterior subhippocampal regions specifically into account. This issue was more recently addressed by Wolk et al. [94], in patients with a MCI and multi-domain MCI, in a study that assessed familiarity and recollection using recognition memory paradigms, in reference to the dual process model of recognition memory [94]. Familiarity was impaired at least as much as recollection and the authors argued that measuring familiarity, spared in normal aging, could provide a specific marker for pathological changes in $\mathrm{AD}$. Interestingly, the volume of ERC/PRC cortices was more highly related to familiarity, compared with that of the $\mathrm{H}$ [95].

In addition, within the theory of binding in the episodic buffer [96], "visual short term memory binding" has been found to be specifically impaired in patients with sporadic and familial $\mathrm{AD}$, as well as in asymptomatic carriers of the mutation [97, 98]. The authors relate no specific neuroanatomical damage to the deficits but speculate that disconnection in $\mathrm{AD}$ could explain their findings. However, it is noteworthy that the perirhinal cortex is thought to play a crucial role in the type of intra-item association tasks that were used in the binding paradigm in these studies [23, 96].

In order to evaluate the dysfunction of the anterior subhippocampal region in patients with early $\mathrm{AD}$, our group developed a visual recognition memory task, the DMS48 [38]. This task is thought to evaluate contextfree memory and is similar to the paradigm used in the experimental studies with animals [51]. Patients failing on the DMS48 display clinical features of early $\mathrm{AD}$, characterized by reduced delayed free recall and reduced cueing efficiency on the FCSR, indicating MTL dysfunction [38]. Using brain SPECT in MCI patients with impaired performance on DMS48 [99], 
we found a functional profile classically reported in early AD [100, 101], with hypoperfusion in the MTL, the posterior cingulate and temporo-parietal cortices. In the same way, using voxel based morphometry, Barbeau and coworkers [102] found a structural profile usually reported in early AD [103-105] with gray matter loss in the MTL and temporo-parietal cortex and a correlation between performance on the DMS48 and grey matter density in anterior subhippocampal structures. Moreover, using proton magnetic resonance spectroscopy, we found reduced MTL NAA/mIno ratios, associated with the severity of pathological changes in AD, only in the MTL of aMCI patients with impaired performance on the DMS48 [106]. In this study, clinical 6-year follow-up data indicated that impaired performance on the DMS48 could predict conversion to $\mathrm{AD}$ with a sensitivity and specificity of $81.8 \%$.

Taken together, the tasks mentioned in this section mainly evaluate context-free memory, either through anterograde learning of single items (like words and pictures), but also retrograde semantic memory. Impaired performance is therefore likely to reflect dysfunction of an anterior mesiotemporal network that supports object-based context-free memory.

Concerning list learning tests assessing the recall of words, commonly used in many studies on $\mathrm{AD}$, we argue that they are not "episodic" per se, as clearly pointed out by Endel Tulving in the foreword of this article [4]. None of these tasks requires mental travel through time, which is a hallmark of episodic memory. Also, subjects are in the same context during recall as they were during encoding (both spatially, sitting in front of a desk, and even temporally since the neuropsychological examination occurs over a limited period of time). If the specific episode ("when" and "where") of stimulus presentation was tested, the subject would be asked to provide contextual information about "where" and "when" these words were learned. Moreover, it is likely that memory processes like recollection and recall can be dissociated [64, 69]. Recollection is a set of processes activated during retrieval from autobiographical episodic memory which requires remembering contextual details of a specific episode in which these words were learned and are defining features of episodic memory. By contrast, recall is a general competency that allows retrieving any information from memory without necessarily referring to context (e.g., when trying to recall the name the capital of Spain most people will not remember in which context they learned that it is Madrid). Additional evidence to support a relationship between word list learning and context-free memory comes from a recent study from our group using resting state fMRI that found positive correlations between connectivity of the anterior MTL network, including anterior subhippocampal structures, and performance on word list learning tasks and visual recognition memory tasks (the DMS48) [107]. Therefore, although it is possible that these word-list learning tasks are partly of "episodic" nature, we argue that the largest component is context-free and depends on anterior subhippocampal structures.

\section{Implications for dysfunction of memory systems in predementia $A D$}

To sum up, which memory systems are selectively impaired in predementia AD? Can recent findings on segregated MTL neural networks implicated in declarative memory contribute to the understanding of the memory dysfunction of the earliest stages of AD? Could tau pathology in the earliest stages of the disease interfere with the function of the anterior MTL network and thereby lead to an impairment of context-free memory?

We reviewed studies in rodents, non-human primates, and from human studies in patients with brain damage, as well as more recent findings from connectivity studies using resting-state fMRI, that provide evidence for an anatomical and functional segregation of two distinct parallel neural networks implicating the MTL, initially described in the visual domain, a ventral visual processing stream dealing with perceptive attributes, or "what", and a dorsal visual processing stream, dealing with spatial attributes, or "where" [108]. Anterior subhippocampal structures like the PRC, where NFT first appear, the lateral ERC cortices as well as the anterior $\mathrm{H}$, and the TPC are integrated into an "anterior MTL network" and contribute to context-free memory. By contrast, the medial ERC, the $\mathrm{PHC}$, the posterior $\mathrm{H}$, where NFT appear at the later limbic stage of $\mathrm{AD}$, as well as the posterior cingulate cortex are part of a "posterior MTL network" that plays a critical role in context-rich memory.

It has been suggested that entorhinal lesions in AD lead to the isolation of the hippocampal formation through functional deafferentation "no less devastating with regard to memory than removal or destruction of the entire structure, thus contributing to the contextual memory defect that is a major component of the amnesia in Alzheimer's disease" [109]. In contrast with this view, the evidence for distinct MTL networks raises the question of whether NFT in the transentorhinal cortex and the entorhinal cortex could 
selectively lead to impaired interaction between the "anterior MTL network" and the H, mainly resulting in deficits of context-free memory. If this was the case, other memory functions of the $\mathrm{H}$, as mediated through the posterior MTL network, and particularly contextrich episodic memory, could remain relatively intact during the very early stages of AD.

We here presented evidence for impaired contextfree memory in predementia AD. However, there is also evidence for impaired context-rich memory and for dysfunction of brain regions within the posterior MTL network in patients at risk for AD. In particular, patients with questionable dementia who declined to $\mathrm{AD}$ on follow-up were shown to be impaired on a spatial short term memory task, the CANTAB Paired Associates Learning (PAL). It was argued that impaired performance on this task could be a marker of early neuropathological abnormalities in the $\mathrm{H}[110$, 111]. Nestor et al. [112] proposed that amnesia seen in $\mathrm{MCI}$ and $\mathrm{AD}$ is a consequence of the disruption of critical focal nodes within a limbic-diencephalic network that includes the MTL, mammillary bodies, dorsomedial thalamus, and posterior cingulate [112]. Using brain imaging, additional evidence was presented that impaired episodic memory is associated with dysfunction of this network, thereby arguing that the episodic

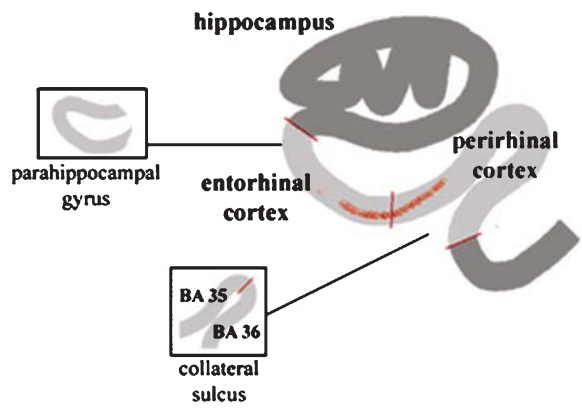

subhippocampal stage of $\mathrm{AD}$
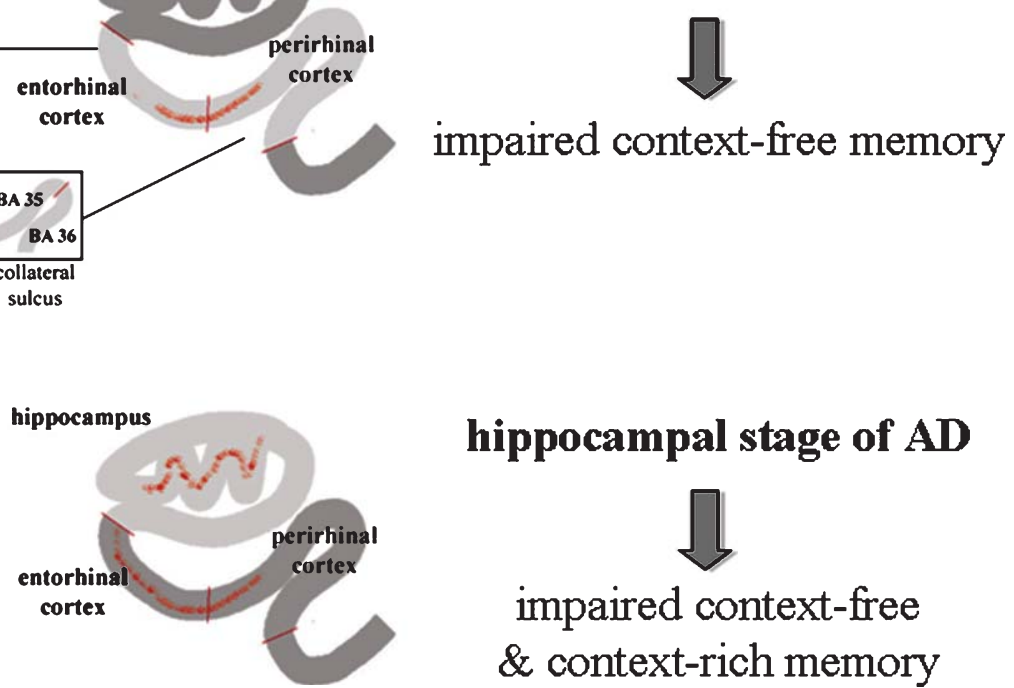

\section{impaired context-free memory}

memory deficit could not only be explained by the degree of MTL damage alone [113]. In this line of thought, it has recently been demonstrated that aspects of topographical memory are impaired in the earliest stages of the disease [114, 115].

Our suggestion to reconcile these views is to integrate these findings into a model that takes into account the localization and the temporal sequence of the lesions in early AD. Since NFT initially appear in anterior subhippocampal areas, it is possible that the first detectable signs during the transentorhinal stage of AD (i.e., Braak and Braak's stages I and II) lead to a selective impairment of the "anterior MTL network" implicated in impaired context-free memory [107] resulting in impaired performance on tasks assessing familiarity based recognition and word-list learning. When NFT, at the limbic stage of AD (i.e., Braak and Braak stages III and IV), are found in both anterior subhippocampal regions, as well as the $\mathrm{H}$, dysfunction of the "posterior MTL network" may lead to impaired context-rich memory (Fig. 2).

The "transentorhinal" stages I-II may begin years and even decades before the diagnosis of AD [116] and were first considered to be clinically "silent" [13]. However, there is also evidence from clinicopathological studies that slight symptoms can already

Fig. 2. Successive stages that take into account memory systems as well as the localization and the temporal sequence of the lesions within the MTL in early AD (coronal view). The subhippocampal stage of AD (Braak and Braak's stages I and II) may lead to a selective impairment of the "anterior MTL network" resulting in impaired context-free memory. In the limbic stage of AD (i.e., Braak and Braak stages III and IV), when NFT are found in both anterior subhippocampal regions, as well as the hippocampus, dysfunction of the "posterior MTL network" may additionally lead to impaired context-rich memory. NFT are schematically represented by red dots. MTL=mesial temporal lobe. NFT =neurofibrillary tangles. 
be detected [117]. Moreover, prospective neuropathological studies have since shown that several of these individuals were diagnosed with amnestic MCI within a year of death $[12,118]$. As a severe deficit in contextfree memory has been shown to be compatible with independence in daily life $[66,69]$, it is possible that difficulties naming people, moderate loss of semantic information, or mild difficulties in learning new factual knowledge leads to consider these patients as being "asymptomatic". By contrast, focal $\mathrm{H}$ lesions leading to impaired context-rich memory are known to severely interfere with autonomy [56]. Patients at the limbic stage of $\mathrm{AD}$, with impaired episodic or context-rich memory, leading to memory loss for personal experiences or spatial disorientation, are more likely to be considered as being symptomatic.

The hypothesis that tau deposition in the anterior subhippocampal region during the earliest stages of AD will lead to dysfunction of neural networks implicated in context-free memory remains however to be confirmed, with a clear demonstration that context-free memory in patients with predementia AD is related to dysfunction of the anterior MTL network (see Table 2 for a list of testable hypotheses). In addition, longitudinal studies are needed in order to establish if this dysfunction predates context-rich memory related to dysfunction of the posterior MTL network. Studies that currently address this issue are mainly being conducted in patients with MCI, most of whom have already reached the limbic stage of AD [12]. Furthermore, several methodological issues have to be resolved. Standardized tasks assessing anterograde, strictly episodic, memory are not available in a clinical setting. Also, tasks assessing context-free and contextrich memory have to be matched for difficulty [64]. Moreover these comparisons have to take into account that some tasks assess retrograde memory (usually semantic tasks), while others assess anterograde memory. The hypothesis should be tested in longitudinal

Table 2

Testable hypotheses suggested in this hypothesis article

1. Context-free memory is impaired before context-rich memory at the transentorhinal stage of $\mathrm{AD}$

2. Context-free memory and context-rich memory are impaired at the hippocampal stage of $\mathrm{AD}$

3. The onset of the hippocampal stage is concomitant with decreasing autonomy

4. The extent of context-free and context-rich memory impairment correlates with NFT burden and topography

5. The efficiency of drugs that target NFTs could be tested by assessing the extent of context-free and context-rich memory impairment in longitudinal studies studies that focus on patients with preclinical AD with signs of amyloidosis and of neurodegeneration [119], a proportion of whom are likely to be at the transentorhinal stage of AD. However, this hypothesis only applies to the most frequent amnestic phenotype of $\mathrm{AD}$ with predominant MTL dysfunction thought to be associated with the $\varepsilon 4$ allele of apolipoprotein $\mathrm{E}$, as well as other factors that remain to be identified [24, 120-123], while it does not apply to other "non-memory phenotypes" of AD where lesions first appear in neocortical regions and that appear to be independent from the $\varepsilon 4$ allele of apolipoprotein E [124-128].

Using neuropsychological tasks that are based on studies in animals and that are known to evaluate the function of neural networks involved in neuropathological processes should be considered for diagnostic purposes in neurodegenerative diseases. Such a translational approach, aiming at identifying a "cognitive biomarker", is most likely to contribute to early diagnosis. These cognitive markers could also be used as longitudinal markers to monitor disease progression during drug trials. In this context, it will be crucial to assess if tasks evaluating context-free memory may detect $\mathrm{AD}$ related pathology earlier than those evaluating context-rich memory.

Finally, the question as to the "episodic" nature of "episodic memory tasks" arises. That predementia AD is characterized by an impairment of episodic memory is predominantly based on the assumption that laboratory experiments of verbal and picture learning deal with episodic memory. As outlined in the introductory words, laboratory experiments deal with "what" the subject had to learn and two important features, "where" and "what" of episodic memory are missing in these tasks [4]. In fact, these so called episodic memory tasks may rather evaluate the anterograde aspects of context-free memory.

\section{ACKNOWLEDGMENTS}

The research that lead to this hypothesis article was supported by AP-HM PHRC 2001, France Alzheimer, CNRS (UMR 6612), Inserm (U751) and a Marie Curie grant from the European Commission (BMH4CT965032) to MD. We would like to thank Maryline Blanchon for editorial assistance with this manuscript.

Authors' disclosures available online (http://www.jalz.com/disclosures/view.php?id=904). 


\section{REFERENCES}

[1] Tulving E (1983) Elements of Episodic Memory. Oxford. Clarendon Press.

[2] Clayton NS, Dickinson A (1998) Episodic-like memory during cache recovery by scrub jays. Nature 395, 272-274.

[3] Nyberg L, McIntosh AR, Houle S, Nilsson LG, Tulving E (1996) Activation of medial temporal structures during episodic memory retrieval. Nature 380, 715-717.

[4] Tulving E (2002) Episodic memory: From mind to brain. Annu Rev Psychol 53, 1-25.

[5] Seeley WW, Crawford RK, Zhou J, Miller BL, Greicius MD (2009) Neurodegenerative diseases target large-scale human brain networks. Neuron 62, 42-52.

[6] Palop JJ, Chin J, Mucke L (2006) A network dysfunction perspective on neurodegenerative diseases. Nature $\mathbf{4 4 3}$, 768-773.

[7] Hyman BT, Van Hoesen GW, Damasio AR (1990) Memoryrelated neural systems in Alzheimer's disease: an anatomic study. Neurology 40, 1721-1730.

[8] Landau SM, Harvey D, Madison CM, Reiman EM, Foster NL, Aisen PS, Petersen RC, Shaw LM, Trojanowski JQ, Jack CR, Jr, Weiner MW, Jagust J (2010) Comparing predictors of conversion and decline in mild cognitive impairment. Neurology 75, 230-238.

[10] Gomez-Isla T, Hollister R, West H, Mui S, Growdon JH, Petersen RC, Parisi JE, Hyman BT (1997) Neuronal loss correlates with but exceeds neurofibrillary tangles in Alzheimer's disease. Ann Neurol 41, 17-24.

[11] Arriagada PV, Growdon JH, Hedley-Whyte ET, Hyman BT (1992) Neurofibrillary tangles but not senile plaques parallel duration and severity of Alzheimer's disease. Neurology $\mathbf{4 2}$, 631-639.

[12] Bennett DA, Schneider JA, Bienias JL, Evans DA, Wilson RS (2005) Mild cognitive impairment is related to Alzheimer disease pathology and cerebral infarctions. Neurology 64, 834-841.

[13] Braak H, Braak E (1991) Neuropathological stageing of Alzheimer-related changes. Acta Neuropathol 82, 239259.

[14] Delacourte A, David JP, Sergeant N, Buee L, Wattez A, Vermersch P, Ghozali F, Fallet-Bianco C, Pasquier F, Lebert F, Petit H, Di Menza C (1999) The biochemical pathway of neurofibrillary degeneration in aging and Alzheimer's disease. Neurology 52, 1158-1165.

[15] Cohen NJ, Squire LR (1980) Preserved learning and retention of pattern-analyzing skill in amnesia: Dissociation of knowing how and knowing that. Science 210, 207-210.

[16] Tulving E (1972) Episodic and semantic memory. In Organisation of memory, Academic Press, New York and London.

[17] Collie A, Maruff P (2000) The neuropsychology of preclinical Alzheimer's disease and mild cognitive impairment. Neurosci Biobehav Rev 24, 365-374.

[18] Bondi MW, Jak AJ, Delano-Wood L, Jacobson MW, Delis DC, Salmon DP (2008) Neuropsychological contributions to the early identification of Alzheimer's disease. Neuropsychol Rev 18, 73-90.

[19] Dubois B, Feldman HH, Jacova C, Dekosky ST, BarbergerGateau P, Cummings J, Delacourte A, Galasko D, Gauthier S, Jicha G, Meguro K, O’Brien J, Pasquier F, Robert P, Rossor M, Salloway S, Stern Y, Visser PJ, Scheltens P (2007) Research criteria for the diagnosis of Alzheimer's disease: revising the NINCDS-ADRDA criteria. Lancet Neurol 6 , 734-746.
[20] Mishkin M, Suzuki WA, Gadian DG, Vargha-Khadem F (1997) Hierarchical organization of cognitive memory. Philos Trans R Soc Lond B Biol Sci 352, 1461-1467.

[21] Eichenbaum H, Schoenbaum G, Young B, Bunsey M (1996) Functional organization of the hippocampal memory system. Proc Natl Acad Sci U S A 93, 13500-13507.

[22] Aggleton JP, Brown MW (2006) Interleaving brain systems for episodic and recognition memory. Trends Cogn Sci 10, 455-463.

[23] Mayes A, Montaldi D, Migo E (2007) Associative memory and the medial temporal lobes. Trends Cogn Sci 11, 126135.

[24] Galton CJ, Patterson K, Xuereb JH, Hodges JR (2000) Atypical and typical presentations of Alzheimer's disease: A clinical, neuropsychological, neuroimaging and pathological study of 13 cases. Brain 123 Pt 3, 484-498.

[25] Taylor KI, Probst A (2008) Anatomic localization of the transentorhinal region of the perirhinal cortex. Neurobiol Aging 29, 1591-1596.

[26] Van Hoesen GW, Hyman BT, Damasio AR (1991) Entorhinal cortex pathology in Alzheimer's disease. Hippocampus 1, 1-8.

[27] Bobinski M, de Leon MJ, Tarnawski M, Wegiel J, Reisberg B, Miller DC, Wisniewski HM (1998) Neuronal and volume loss in CA1 of the hippocampal formation uniquely predicts duration and severity of Alzheimer disease. Brain Res $\mathbf{8 0 5}$, 267-269.

[28] deToledo-Morrell L, Stoub TR, Bulgakova M, Wilson RS, Bennett DA, Leurgans S, Wuu J, Turner DA (2004) MRIderived entorhinal volume is a good predictor of conversion from MCI to AD. Neurobiol Aging 25, 1197-1203.

[29] Killiany RJ, Gomez-Isla T, Moss M, Kikinis R, Sandor T, Jolesz F, Tanzi R, Jones K, Hyman BT, Albert MS (2000) Use of structural magnetic resonance imaging to predict who will get alzheimer's disease. Ann Neurol 47, 430-439.

[30] Dickerson BC, Goncharova I, Sullivan MP, Forchetti C, Wilson RS, Bennett DA, Beckett LA, deToledo-Morrell L (2001) MRI-derived entorhinal and hippocampal atrophy in incipient and very mild Alzheimer's disease. Neurobiol Aging 22, 747-754.

[31] Du AT, Schuff N, Amend D, Laakso MP, Hsu YY, Jagust WJ, Yaffe K, Kramer JH, Reed B, Norman D, Chui HC, Weiner MW (2001) Magnetic resonance imaging of the entorhinal cortex and hippocampus in mild cognitive impairment and Alzheimer's disease. J Neurol Neurosurg Psychiatry 71, 441-447.

[32] Stoub TR, Bulgakova M, Leurgans S, Bennett DA, Fleischman D, Turner DA, deToledo-Morrell L (2005) MRI predictors of risk of incident Alzheimer disease: A longitudinal study. Neurology 64, 1520-1524.

[33] Suzuki WA, Amaral DG (1994) Topographic organization of the reciprocal connections between the monkey entorhinal cortex and the perirhinal and parahippocampal cortices. $J$ Neurosci 14, 1856-1877.

[34] Suzuki WA, Amaral DG (1994) Perirhinal and parahippocampal cortices of the macaque monkey: cortical afferents. J Comp Neurol 350, 497-533.

[35] Blaizot X, Mansilla F, Insausti AM, Constans JM, SalinasAlaman A, Pro-Sistiaga P, Mohedano-Moriano A, Insausti $\mathrm{R}$ (2010) The human parahippocampal region: I. temporal pole cytoarchitectonic and MRI correlation. Cereb Cortex 20, 2198-2212.

[36] Ding SL, Van Hoesen GW (2010) Borders, extent, and topography of human perirhinal cortex as revealed using 
multiple modern neuroanatomical and pathological markers. Hum Brain Mapp 31, 1359-1379.

[37] Insausti R, Juottonen K, Soininen H, Insausti AM, Partanen K, Vainio P, Laakso MP, Pitkanen A (1998) MR volumetric analysis of the human entorhinal, perirhinal, and temporopolar cortices. AJNR Am J Neuroradiol 19, 659-671.

[38] Barbeau E, Didic M, Tramoni E, Felician O, Joubert S, Sontheimer A, Ceccaldi M, Poncet M (2004) Evaluation of visual recognition memory in MCI patients. Neurology 62, 1317-1322.

[39] Martin-Elkins CL, Horel JA (1992) Cortical afferents to behaviorally defined regions of the inferior temporal and parahippocampal gyri as demonstrated by WGA-HRP. $J$ Comp Neurol 321, 177-192.

[40] Lavenex P, Amaral DG (2000) Hippocampal-neocortical interaction: A hierarchy of associativity. Hippocampus $\mathbf{1 0}$, $420-430$.

[41] Insausti R, Amaral DG, Cowan WM (1987) The entorhinal cortex of the monkey: II. Cortical afferents. J Comp Neurol 264, 356-395.

[42] Insausti R, Amaral DG, Cowan WM (1987) The entorhinal cortex of the monkey: III. Subcortical afferents. J Comp Neurol 264, 396-408.

[43] Witter MP, Amaral DG (1991) Entorhinal cortex of the monkey: V. Projections to the dentate gyrus, hippocampus, and subicular complex. J Comp Neurol 307, 437-459.

[44] Burwell RD, Amaral DG (1998) Cortical afferents of the perirhinal, postrhinal, and entorhinal cortices of the rat. $J$ Comp Neurol 398, 179-205.

[45] Burwell RD (2000) The parahippocampal region: Corticocortical connectivity. Ann NY Acad Sci 911, 25-42.

[46] Furtak SC, Wei SM, Agster KL, Burwell RD (2007) Functional neuroanatomy of the parahippocampal region in the rat: The perirhinal and postrhinal cortices. Hippocampus 17, 709-722.

[47] Witter MP, Naber PA, van Haeften T, Machielsen C, Rombouts SA, Barkhof F, Scheltens P, Lopes da Silva FH (2000) Cortico-hippocampal communication by way of parallel parahippocampal-subicular pathways. Hippocampus 10, 398-410.

[48] Kahn I, Andrews-Hanna JR, Vincent JL, Snyder AZ, Buckner RL (2008) Distinct cortical anatomy linked to subregions of the medial temporal lobe revealed by intrinsic functional connectivity. J Neurophysiol 100, 129-139.

[49] Scoville WB, Milner B (1957) Loss of recent memory after bilateral hippocampal lesions. J Neurol Neurosurg Psychiatry 20, 11-21.

[50] Squire LR, Bayley PJ (2007) The neuroscience of remote memory. Curr Opin Neurobiol 17, 185-196.

[51] Meunier M, Bachevalier J, Mishkin M, Murray EA (1993) Effects on visual recognition of combined and separate ablations of the entorhinal and perirhinal cortex in rhesus monkeys. J Neurosci 13, 5418-5432.

[52] Murray EA, Bussey TJ (1999) Perceptual-mnemonic functions of the perirhinal cortex. Trends Cogn Sci 3, 142-151.

[53] McDonald RJ, White NM (1993) A triple dissociation of memory systems: Hippocampus, amygdala, and dorsal striatum. Behav Neurosci 107, 3-22.

[54] McClelland JL, McNaughton BL, O'Reilly RC (1995) Why there are complementary learning systems in the hippocampus and neocortex: Insights from the successes and failures of connectionist models of learning and memory. Psychol Rev 102, 419-457.

[55] Miyashita Y, Kameyama M, Hasegawa I, Fukushima T (1998) Consolidation of visual associative long-term mem- ory in the temporal cortex of primates. Neurobiol Learn Mem 70, 197-211.

[56] Vargha-Khadem F, Gadian DG, Watkins KE, Connelly A Van Paesschen W, Mishkin M (1997) Differential effects of early hippocampal pathology on episodic and semantic memory. Science 277, 376-380.

[57] Aggleton JP, Brown MW (1999) Episodic memory amnesia and the hippocampal-anterior thalamic axis. Behav Brain Sci 22, 425-444; discussion 444-489.

[58] Eichenbaum H, Yonelinas AP, Ranganath C (2007) The medial temporal lobe and recognition memory. Аnпи Rev Neurosci 30, 123-152.

[59] Rugg MD, Curran T (2007) Event-related potentials and recognition memory. Trends Cogn Sci 11, 251-257.

[60] Mayes AR, Holdstock JS, Isaac CL, Hunkin NM, Roberts N (2002) Relative sparing of item recognition memory in a patient with adult-onset damage limited to the hippocampus. Hippocampus 12, 325-340.

[61] Aggleton JP, Vann SD, Denby C, Dix S, Mayes AR, Roberts N, Yonelinas AP (2005) Sparing of the familiarity component of recognition memory in a patient with hippocampal pathology. Neuropsychologia 43, 1810-1823.

[62] Barbeau EJ, Felician O, Joubert S, Sontheimer A, Ceccaldi $\mathrm{M}$, Poncet M (2005) Preserved visual recognition memory in an amnesic patient with hippocampal lesions. Hippocampus 15, 587-596.

[63] Lebrun-Givois C, Guillery-Girard B, Thomas-Anterion C, Laurent B (2008) Knowing without remembering: the contribution of developmental amnesia. Rev Neurol (Paris) 164 Suppl 3, S114-S118.

[64] Tramoni E, Felician O, Barbeau EJ, Guedj E, Guye M, Bartolomei F, Ceccaldi M (2011) Long-term consolidation of declarative memory: Insight from temporal lobe epilepsy. Brain 134, 816-831.

[65] Bastin C, Linden M, Charnallet A, Denby C, Montaldi D, Roberts N, Andrew M (2004) Dissociation between recall and recognition memory performance in an amnesic patient with hippocampal damage following carbon monoxide poisoning. Neurocase 10, 330-344.

[66] Barbeau EJ, Pariente J, Felician O, Puel M (2010) Visual recognition memory: A double anatomo-functional dissociation. Hippocampus, doi: 10.1002/hipo.20848

[67] Bowles B, Crupi C, Mirsattari SM, Pigott SE, Parrent AG, Pruessner JC, Yonelinas AP, Kohler S (2007) Impaired familiarity with preserved recollection after anterior temporal-lobe resection that spares the hippocampus. Proc Natl Acad Sci U S A 104, 16382-16387.

[68] Bowles B, Crupi C, Pigott S, Parrent A, Wiebe S, Janzen L, Kohler S (2010) Double dissociation of selective recollection and familiarity impairments following two different surgical treatments for temporal-lobe epilepsy. Neuropsychologia 48, 2640-2647.

[69] Barbeau EJ, Didic M, Felician O, Tramoni E, Guedj E, Ceccaldi M, Poncet M (2006) Pure progressive amnesia: An atypical amnestic syndrome? Cogn Neuropsychol 23, 1230-1247.

[70] Temple CM, Richardson P (2006) Developmental amnesia Fractionation of developing memory systems. Cogn Neuropsychol 23, 762-788.

[71] Hodges JR, Patterson K, Oxbury S, Funnell E (1992) Semantic dementia progressive fluent aphasia with temporal lobe atrophy. Brain 115, 1783-1806.

[72] Davies RR, Graham KS, Xuereb JH, Williams GB, Hodges JR (2004) The human perirhinal cortex and semantic memory. Eur J Neurosci 20, 2441-2446. 
[73] Desgranges B, Matuszewski V, Piolino P, Chetelat G, Mezenge F, Landeau B, de la Sayette V, Belliard S, Eustache F (2007) Anatomical and functional alterations in semantic dementia: a voxel-based MRI and PET study. Neurobiol Aging 28, 1904-1913.

[74] Martin CB, Bowles B, Mirsattari SM, Kohler S (2011) Selective familiarity deficits after left anterior temporal-lobe removal with hippocampal sparing are material specific. Neuropsychologia 49, 1870-1878.

[75] Fox NC, Warrington EK, Seiffer AL, Agnew SK, Rossor MN (1998) Presymptomatic cognitive deficits in individuals at risk of familial Alzheimer's disease. A longitudinal prospective study. Brain 121, 1631-1639.

[76] Knight WD, Ahsan RL, Jackson J, Cipolotti L, Warrington EK, Fox NC, Rossor MN (2009) Pure progressive amnesia and the APPV717G mutation. Alzheimer Dis Assoc Disord 23, 410-414.

[77] Jacobs DM, Sano M, Dooneief G, Marder K, Bell KL, Stern Y (1995) Neuropsychological detection and characterization of preclinical Alzheimer's disease. Neurology 45 957-962.

[78] Elias MF, Beiser A, Wolf PA, Au R, White RF, D'Agostino RB (2000) The preclinical phase of Alzheimer's disease: A 22 year prospective study of the framingham cohort. Arch Neurol 57, 808-813.

[79] Backman L, Small J, Fratiglioni L (2001) Stability of the preclinical episodic memory deficit in Alzheimer's disease. Brain 124, 96-102.

[80] Tierney MC, Yao C, Kiss A, McDowell I (2005) Neuropsychological tests accurately predict incident Alzheimer disease after 5 and 10 years. Neurology 64, 1853-1859.

[81] Amieva H, Le Goff M, Millet X, Orgogozo JM, Peres K, Barberger-Gateau P, Jacqmin-Gadda H, Dartigues JF (2008) Prodromal Alzheimer's disease: successive emergence of the clinical symptoms. Ann Neurol 64, 492-498.

[82] Tabert MH, Manly JJ, Liu X, Pelton GH, Rosenblum S, Jacobs M, Zamora D, Goodkind M, Bell K, Stern Y, Devanand DP (2006) Neuropsychological prediction of conversion to Alzheimer disease in patients with mild cognitive impairment. Arch Gen Psychiatry 63, 916-924.

[83] Sarazin M, Berr C, De Rotrou J, Fabrigoule C, Pasquier F, Legrain S, Michel B, Puel M, Volteau M, Touchon J, Verny M, Dubois B (2007) Amnestic syndrome of the medial temporal type identifies prodromal AD: a longitudinal study. Neurology 69, 1859-1867.

[84] Eustache F, Desgranges B, Giffard B, de la Sayette V, Baron JC (2001) Entorhinal cortex disruption causes memory deficit in early Alzheimer's disease as shown by PET. Neuroreport 12, 683-685.

[85] Vogel A, Gade A, Stokholm J, Waldemar G (2005) Semantic memory impairment in the earliest phases of Alzheimer's disease. Dement Geriatr Cogn Disord 19, 75-81

[86] Thompson SA, Graham KS, Patterson K, Sahakian BJ, Hodges JR (2002) Is knowledge of famous people disproportionately impaired in patients with early and questionable Alzheimer's disease? Neuropsychology 16, 344358.

[87] Estevez-Gonzalez A, Garcia-Sanchez C, Boltes A, Otermin P, Pascual-Sedano B, Gironell A, Kulisevsky J (2004) Semantic knowledge of famous people in mild cognitive impairment and progression to Alzheimer's disease. Dement Geriatr Cogn Disord 17, 188-195.

[88] Dudas RB, Clague F, Thompson SA, Graham KS, Hodges JR (2005) Episodic and semantic memory in mild cognitive impairment. Neuropsychologia 43, 1266-1276.
[89] Adlam AL, Bozeat S, Arnold R, Watson P, Hodges JR (2006) Semantic knowledge in mild cognitive impairment and mild Alzheimer's disease. Cortex 42, 675-684.

[90] Joubert S, Felician O, Barbeau EJ, Didic M, Poncet M, Ceccaldi M (2008) Patterns of semantic memory impairment in Mild Cognitive Impairment. Behav Neurol 19, 35-40.

[91] Cuetos F, Rodriguez-Ferreiro J, Menendez M (2009) Semantic markers in the diagnosis of neurodegenerative dementias. Dement Geriatr Cogn Disord 28, 267-274.

[92] Joubert S, Brambati SM, Ansado J, Barbeau EJ, Felician O, Didic M, Lacombe J, Goldstein R, Chayer C, Kergoat MJ (2010) The cognitive and neural expression of semantic memory impairment in mild cognitive impairment and early Alzheimer's disease. Neuropsychologia 48, 978-988.

[93] Venneri A, McGeown WJ, Hietanen HM, Guerrini C, Ellis AW, Shanks MF (2008) The anatomical bases of semantic retrieval deficits in early Alzheimer's disease. Neuropsychologia 46, 497-510.

[94] Wolk DA, Signoff ED, Dekosky ST (2008) Recollection and familiarity in amnestic mild cognitive impairment: A global decline in recognition memory. Neuropsychologia $\mathbf{4 6}$, 1965-1978.

[95] Wolk DA, Dunfee KL, Dickerson BC, Aizenstein HJ, Dekosky ST (2011) A medial temporal lobe division of labor: Insights from memory in aging and early Alzheimer disease. Hippocampus 21, 461-466.

[96] Baddeley A, Allen R, Vargha-Khadem F (2010) Is the hippocampus necessary for visual and verbal binding in working memory? Neuropsychologia 48, 1089-1095.

[97] Parra MA, Abrahams S, Fabi K, Logie R, Luzzi S, Della Sala $S$ (2009) Short-term memory binding deficits in Alzheimer's disease. Brain 132, 1057-1066.

[98] Parra MA, Abrahams S, Logie RH, Mendez LG, Lopera F, Della Sala S (2010) Visual short-term memory binding deficits in familial Alzheimer's disease. Brain 133, 27022713.

[99] Guedj E, Barbeau EJ, Didic M, Felician O, de Laforte C, Ceccaldi M, Mundler O, Poncet M (2006) Identification of subgroups in amnestic mild cognitive impairment. Neurology 67, 356-358.

[100] Borroni B, Anchisi D, Paghera B, Vicini B, Kerrouche N, Garibotto V, Terzi A, Vignolo LA, Di Luca M, Giubbini R, Padovani A, Perani D (2006) Combined 99mTc-ECD SPECT and neuropsychological studies in MCI for the assessment of conversion to AD. Neurobiol Aging 27, 2431 .

[101] Nobili F, De Carli F, Frisoni GB, Portet F, Verhey F, Rodriguez G, Caroli A, Touchon J, Morbelli S, Guerra UP, Dessi B, Brugnolo A, Visser PJ (2009) SPECT predictors of cognitive decline and Alzheimer's disease in mild cognitive impairment. J Alzheimers Dis 17, 761-772.

[102] Barbeau EJ, Ranjeva JP, Didic M, Confort-Gouny S, Felician O, Soulier E, Cozzone PJ, Ceccaldi M, Poncet M (2008) Profile of memory impairment and gray matter loss in amnestic mild cognitive impairment. Neuropsychologia 46, 1009-1019.

[103] Karas GB, Scheltens P, Rombouts SA, Visser PJ, van Schijndel RA, Fox NC, Barkhof F (2004) Global and local gray matter loss in mild cognitive impairment and Alzheimer's disease. Neuroimage 23, 708-716.

[104] Desikan RS, Cabral HJ, Fischl B, Guttmann CR, Blacker D, Hyman BT, Albert MS, Killiany RJ (2009) Temporoparietal MR imaging measures of atrophy in subjects with mild cognitive impairment that predict subsequent diagnosis of Alzheimer disease. AJNR Am J Neuroradiol 30, 532-538. 
[105] McDonald CR, McEvoy LK, Gharapetian L, FennemaNotestine C, Hagler DJ, Jr., Holland D, Koyama A, Brewer JB, Dale AM (2009) Regional rates of neocortical atrophy from normal aging to early Alzheimer disease. Neurology 73, 457-465.

[106] Didic M, Ranjeva JP, Barbeau E, Confort-Gouny S, Fur YL, Felician O, Mancini J, Poncet M, Ceccaldi M, Cozzone $P$ (2010) Impaired visual recognition memory in amnestic mild cognitive impairment is associated with mesiotemporal metabolic changes on magnetic resonance spectroscopic imaging. J Alzheimers Dis 22, 1269-1279.

[107] Gour N, Ranjeva JP, Ceccaldi M, Confort-Gouny S, Barbeau E, Soulier E, Guye M, Didic M, Felician O Basal functional connectivity within the anterior temporal network is associated with performance on declarative memory tasks. Neuroimage 2011, doi:10.1016/j.neuroimage.2011.05.090. In press.

[108] Ungerleider L, Mishkin M (1982) Two cortical visual systems. In Analysis of visual behaviour, MIT Press, Cambridge, 549-586.

[109] Hyman BT, Van Hoesen GW, Damasio AR, Barnes CL (1984) Alzheimer's disease: Cell-specific pathology isolates the hippocampal formation. Science 225, 1168-1170.

[110] Fowler KS, Saling MM, Conway EL, Semple JM, Louis WJ (2002) Paired associate performance in the early detection of DAT. J Int Neuropsychol Soc 8, 58-71.

[111] Blackwell AD, Sahakian BJ, Vesey R, Semple JM, Robbins TW, Hodges JR (2004) Detecting dementia: Novel neuropsychological markers of preclinical Alzheimer's disease. Dement Geriatr Cogn Disord 17, 42-48.

[112] Nestor PJ, Fryer TD, Smielewski P, Hodges JR (2003) Limbic hypometabolism in Alzheimer's disease and mild cognitive impairment. Ann Neurol 54, 343-351.

[113] Nestor PJ, Fryer TD, Hodges JR (2006) Declarative memory impairments in Alzheimer's disease and semantic dementia. Neuroimage 30, 1010-1020.

[114] Bird CM, Chan D, Hartley T, Pijnenburg YA, Rossor MN, Burgess N (2010) Topographical short-term memory differentiates Alzheimer's disease frontotemporal lobar degeneration. Hippocampus 20, 1154-1169.

[115] Pengas G, Hodges JR, Watson P, Nestor PJ (2010) Focal posterior cingulate atrophy in incipient Alzheimer's disease. Neurobiol Aging 31, 25-33.

[116] Braak H, Braak E (1997) Frequency of stages of Alzheimerrelated lesions in different age categories. Neurobiol Aging 18, 351-357.

[117] Gomez-Isla T, Price JL, McKeel DW, Jr., Morris JC, Growdon JH, Hyman BT (1996) Profound loss of layer II entorhinal cortex neurons occurs in very mild Alzheimer's disease. J Neurosci 16, 4491-4500.

[118] Riley KP, Snowdon DA, Markesbery WR (2002) Alzheimer's neurofibrillary pathology and the spectrum of cognitive function: Findings from the nun study. Ann Neurol 51, 567-577.

[119] Sperling RA, Aisen PS, Beckett LA, Bennett DA, Craft S, Fagan AM, Iwatsubo T, Jack CR, Jr., Kaye J, Montine TJ, Park DC, Reiman EM, Rowe CC, Siemers E, Stern Y, Yaffe K, Carrillo MC, Thies B, Morrison-Bogorad M, Wagster MV, Phelps CH (2011) Toward defining the preclinical stages of Alzheimer's disease: Recommendations from the National Institute on Aging-Alzheimer's Association workgroups on diagnostic guidelines for Alzheimer's disease. Alzheimers Dementia 7, 280-292.

[120] Butters MA, Lopez OL, Becker JT (1996) Focal temporal lobe dysfunction in probable Alzheimer's disease predicts a slow rate of cognitive decline. Neurology 46, 687-692.

[121] Reed BR, Mungas DM, Kramer JH, Ellis W, Vinters HV, Zarow C, Jagust WJ, Chui HC (2007) Profiles of neuropsychological impairment in autopsy-defined Alzheimer's disease and cerebrovascular disease. Brain 130, 731739 .

[122] Donix M, Burggren AC, Suthana NA, Siddarth P, Ekstrom AD, Krupa AK, Jones M, Rao A, Martin-Harris L, Ercoli LM, Miller KJ, Small GW, Bookheimer SY (2010) Longitudinal changes in medial temporal cortical thickness in normal subjects with the APOE-4 polymorphism. Neuroimage 53, 37-43.

[123] Mueller SG, Schuff N, Raptentsetsang S, Elman J, Weiner MW (2008) Selective effect of Apo e4 on CA3 and dentate in normal aging and Alzheimer's disease using high resolution MRI at 4 T. Neuroimage $\mathbf{4 2}, 42-48$.

[124] Didic M, Gueriot-Milandre C, Semprez C, Guisiano B, Poncet M (1997) Corrélations entre des sous-types de "Maladie d'Alzheimer probable" et le phénotype de l'Apolipoprotéine E. L'Année Gérontologique - Facts and Research in Gerontology 4, 91-95.

[125] Schott JM, Ridha BH, Crutch SJ, Healy DG, Uphill JB, Warrington EK, Rossor MN, Fox NC (2006) Apolipoprotein e genotype modifies the phenotype of Alzheimer disease. Arch Neurol 63, 155-156.

[126] van der Flier WM, Schoonenboom SN, Pijnenburg YA, Fox NC, Scheltens P (2006) The effect of APOE genotype on clinical phenotype in Alzheimer disease. Neurology 67, 526527.

[127] van der Flier WM, Pijnenburg YA, Fox NC, Scheltens P Early-onset versus late-onset. Alzheimer's disease: The case of the missing APOE epsilon4 allele. Lancet Neurol 10, 280288.

[128] Dickerson BC, Wolk DA (2011) Alzheimer's Disease Neuroimaging Initiative Dysexecutive versus amnesic phenotypes of very mild Alzheimer's disease are associated with distinct clinical, genetic and cortical thinning characteristics. J Neurol Neurosurg Psychiatry 82, 45-51. 